\title{
Fructose-1,6-bisphosphate for improved outcome after hypothermic circulatory arrest in pigs
}

\author{
Pekka Romsi, MD \\ Timo Kaakinen, $\mathrm{MS}^{\mathrm{a}}$ \\ Kai Kiviluoma, MD, $\mathrm{PhD}^{\mathrm{b}}$ \\ Vilho Vainionpää, $\mathrm{MD}, \mathrm{PhD}^{\mathrm{b}}$ \\ Jorma Hirvonen, $\mathrm{MD}, \mathrm{PhD}^{\mathrm{C}}$ \\ Matti Pokela, MS ${ }^{\mathrm{a}}$ \\ Pasi Ohtonen, $\mathrm{MSc}^{\mathrm{a}}$ \\ Fausto Biancari, MD, PhD \\ Matti Nuutinen, $M D, \mathrm{PhD}^{\mathrm{d}}$ \\ Tatu Juvonen, MD, PhD ${ }^{\mathrm{a}}$
}

Objective: Fructose-1,6-bisphosphate is a high-energy intermediate in the anaerobic metabolism. It enhances glycolysis, preserves cellular adenosine triphosphate, and prevents the increase of intracellular calcium during ischemia. The potential neuroprotective effect of fructose-1,6-bisphosphate during hypothermic circulatory arrest was evaluated in a surviving porcine model.

Methods: Twenty-four pigs were randomly assigned to receive two intravenous infusions of either fructose-1,6-bisphosphate $(500 \mathrm{mg} / \mathrm{kg})$ or saline solution. The first infusion was given immediately before a 75-minute period of hypothermic circulatory arrest and the second was given immediately after hypothermic circulatory arrest.

Results: The 7-day survivals were $83.3 \%$ in the fructose-1,6-bisphosphate group and $41.7 \%$ in the control group $(P=.09)$. The treated animals had significantly better postoperative behavioral scores. The administration of fructose-1,6-bisphosphate was associated with higher venous phosphate and sodium levels, lower venous ionized calcium levels, higher blood osmolarity, and a better fluid balance. Intracranial pressure and venous creatine kinase isoenzyme MB were significantly lower in the fructose-1,6-bisphosphate group during rewarming $(P=.01$ and $P=.001$, respectively). Among the treated animals, brain glucose, pyruvate and lactate levels tended to be higher, brain glycerol levels tended to be lower, and the histopathologic score of the brain was significantly lower $(P=.04)$.

Conclusions: Intravenous administration of fructose-1,6-bisphosphate at $500 \mathrm{mg} / \mathrm{kg}$ before and after hypothermic circulatory arrest in a surviving porcine model was associated with better survival, behavioral outcome, and histopathologic score. The observed lower blood creatine kinase isoenzyme MB and brain glycerol levels and the higher brain glucose, pyruvate, and lactate levels in the fructose-1,6-bisphosphate group suggest that this drug has supportive effects on myocardial and brain metabolisms.

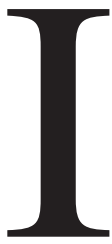

mpairment of oxidative metabolism during brain ischemia is associated with adenosine triphosphate (ATP) deficit and subsequent intracellular calcium ion accumulation, which are considered the main factors leading to severe brain injury. Fructose-1,6-bisphosphate (FDP) is an intermediate in anaerobic glycolysis. It increases the activity of phosphofructokinase, a key enzyme in glycolysis, and of pyruvate kinase and thus enhances glycolysis. Exogenously administered FDP can be metabolized anaerobically. It is a high- 
energy metabolite, because it releases 4 mol ATP for 1 mol FDP, whereas only 2 mol ATP is formed by anaerobic metabolism of $1 \mathrm{~mol}$ glucose. FDP has also been shown to decrease calcium uptake into the cell during ischemia. ${ }^{1,2}$

Several studies have demonstrated that FDP reduces myocardial tissue damage induced by ischemia and reperfusion. ${ }^{2-4}$ There is also some in vitro evidence that FDP prevents the loss of ATP and protects astrocytes from hypoxic injury. ${ }^{5}$ Moreover, the neuroprotective effect of FDP has been observed in several animal models of brain ischemia. ${ }^{6,7}$ However, negative results with the use of FDP have also been reported. ${ }^{8,9}$ We performed this study to evaluate whether FDP has neuroprotective effects in a surviving porcine model of hypothermic circulatory arrest (HCA).

\section{Material and Methods}

Twenty-four female juvenile pigs (age 8-10 weeks) of a native stock were randomly assigned to receive two intravenous infusions of either FDP at $500 \mathrm{mg} / \mathrm{kg}$ or $0.9 \%$ sodium chloride solution. The first infusion of 15-minute duration was given just before a 75minute period of HCA, and the second infusion of 30-minute duration was given immediately at the start of reperfusion.

\section{Preoperative Management}

All animals received humane care in accordance with the "Principles of Laboratory Animal Care" formulated by the National Society for Medical Research and the Guide for the Care and Use of Laboratory Animals prepared by the Institute of Laboratory Animal Resources, National Research Council, and published by the National Academy Press, revised 1996. The study was approved by the Research Animal Care and Use Committee of the University of Oulu.

\section{Anesthesia and Hemodynamic Monitoring}

Anesthesia was induced with ketamine hydrochloride $(10 \mathrm{mg} / \mathrm{kg}$ administered intramuscularly) and midazolam ( $1 \mathrm{mg} / \mathrm{kg}$ administered intramuscularly). A peripheral venous catheter was inserted into the right ear for administration of drugs and to maintain fluid balance with Ringer acetate solution. Anesthesia was deepened with thiopental sodium (125-250 mg administered intravenously), and pancuronium bromide (4 $\mathrm{mg}$ administered intravenously) was given for muscular paralysis. Cefuroxime $(1.5 \mathrm{~g})$ was given as antibiotic prophylaxis at the induction of anesthesia and before extubation 8 hours after the start of rewarming.

After endotracheal intubation, the animals were maintained on positive-pressure ventilation with 50\% oxygen, and anesthesia was maintained with isoflurane (1.2\%-1.3\%). Electrocardiographic monitoring was started. An arterial catheter was positioned into the left femoral artery for arterial pressure monitoring and blood sampling. A thermodilution catheter (CritiCath 7F; Ohmeda $\mathrm{GmbH} \& \mathrm{Co}$, Erlangen, Germany) was placed through the left femoral vein for blood collection, pressure monitoring in the pulmonary artery, and recording of blood temperature and cardiac output. A 10F catheter was placed into the urinary bladder for monitoring of urine output. Blood, rectal, esophageal, epidural, and intracerebral temperatures were monitored continuously.

\section{Brain Microdialysis and Intracerebral Monitoring}

A temperature probe was placed into the epidural space through a cranial hole made on the left side anteriorly to the coronal suture. A catheter for measurement of intracerebral tissue oxygen partial pressure (Revodoxe Brain Oxygen Catheter-Micro-Probe, ref. CC1.SB; GMS Gesellschaft für medizinische Sondentechnik mbH, Mielkendorf, Germany) was inserted through a hole located on the right side anteriorly to the coronal suture. Another temperature probe (Thermocouple Temperature Catheter-Micro-Probe, ref. C8.B; GMS) for the measurement of intracerebral temperature, together with an intracranial pressure-monitoring catheter (Codman Micro-Sensor ICP Transducer; Codman \& Shurtleff, Inc, Raynham, Mass), were placed through a hole located on the left side posteriorly to the coronal suture. Intracerebral temperature and brain tissue oxygen partial pressure were monitored with Licox CMP Monitor (GMS). Intracranial pressure was monitored with Codman ICP Express Monitor (Codman \& Shurtleff).

The microdialysis catheter (CMA 70; CMA/Microdialysis, Stockholm, Sweden) was placed into the brain cortex to a depth of $15 \mathrm{~mm}$ below the dura mater through a hole located on the right side posteriorly to the coronal suture. The catheter was connected to a 2.5-mL syringe placed into a microinfusion pump (CMA 106; CMA/Microdialysis) and perfused with Ringer solution (Perfusion Fluid CNS; CMA/Microdialysis). Samples were collected at different time points. The brain tissue concentrations of glucose, lactate, pyruvate, glutamate, and glycerol were measured immediately after collection by ordinary enzymatic methods with a microdialysis analyzer (CMA 600; CMA/Microdialysis).

\section{Electroencephalographic Monitoring}

Cortical electrical activity was registered by four stainless-steel screw electrodes $5 \mathrm{~mm}$ in diameter implanted in the skull over the parietal and frontal areas of the cortex with a digital electroencephalographic (EEG) recorder (Nervus, Reykjavik, Iceland) and an amplifier (Magnus EEG 32/8, Reykjavik, Iceland). Sampling frequency was $256 \mathrm{~Hz}$, and bandwidth was 1.6 to $70 \mathrm{~Hz}$. All four EEG electrodes were referenced to another screw electrode, which, together with a ground screw electrode, was implanted over the frontal sinuses.

The isoflurane level was adjusted so that the EEG showed a steady burst-suppression pattern. Isoflurane end-tidal concentration was kept at this steady level until the end of monitoring. The EEG tracing was recorded for 10 minutes before the cooling perfusion to get a baseline recording of steady burst-suppression activity. After HCA, EEG recording was restarted and continued until extubation. The duration of bursts were measured from 5-minute EEG samples at 1-hour intervals with a custom automatic analysis program. Artifact periods were excluded from each 5 -minute sample, and after that the sum of burst durations was counted as a percentage of the sum of artifact-free EEG in this sample. This percentage was used as a measure of EEG activity in the analysis.

\section{Cardiopulmonary Bypass}

Through a right thoracotomy in the fourth intercostal space, the right internal thoracic vessels were ligated, the pericardium was opened, and the heart and the great vessels were exposed. A membrane oxygenator (Midiflow D 705; Dideco SpA, Mirandola, 
Italy) was primed with $1 \mathrm{~L}$ Ringer acetate and heparin (5000 IU). After systemic heparinization (500 IU/kg), the ascending aorta was cannulated with a $16 \mathrm{~F}$ arterial cannula, and the right atrial appendage was cannulated with a single $24 \mathrm{~F}$ atrial cannula. Nonpulsatile cardiopulmonary bypass (CPB) was initiated and maintained with $100 \%$ oxygen during cooling and rewarming periods at a flow rate of $100 \mathrm{~mL} /(\mathrm{kg} \cdot \mathrm{min})$. The CPB flow was adjusted to maintain a perfusion pressure of $50 \mathrm{~mm} \mathrm{Hg}$. A $12 \mathrm{~F}$ intracardiac sump cannula was positioned in the left ventricle through the apex of the heart for decompression of the left side of the heart during CPB. A heat exchanger was used for core cooling. The $\mathrm{pH}$ was maintained with alpha-stat principles at $7.40 \pm 0.05$, with $\mathrm{PaCO}_{2}$ at 4.0 to $5.0 \mathrm{kPa}$ uncorrected for temperature.

\section{Drug Administration}

The molecular weight of FDP is $336.082 \mathrm{kd}$. The drug (Esafosfina; Biomedica Foscama Industria Chimico-Farmaceutica SpA, Ferentino, Italy) was stored at room temperature in $100-\mathrm{mL}$ bottles containing FDP (100 g/L), inorganic phosphate ion $(46 \mathrm{mmol} / \mathrm{L}$, $1.43 \mathrm{~g})$, sodium ion ( $44 \mathrm{mmol} / \mathrm{L}, 2.64 \mathrm{~g})$, and fructose $(22 \mathrm{mmol} / \mathrm{L}$, $4.0 \mathrm{~g}$ ). The liquid was sterile and colorless, its $\mathrm{pH}$ was 3.5 to 3.8 , and its osmolarity was $620 \mathrm{mmol} / \mathrm{L}$. Before infusion, the drug was neutralized with sodium hydroxide $(34 \mathrm{~mL}$ sodium hydroxide per $200 \mathrm{~mL}$ FDP) to yield a $\mathrm{pH}$ of 6.3. The sodium hydroxide solution contained sodium ion at $2 \mathrm{~mol} / \mathrm{L}$. The placebo consisted of a corresponding volume $(5 \mathrm{~mL} / \mathrm{kg})$ of isotonic sodium chloride (sodium ion at $150 \mathrm{mmol} / \mathrm{L}$ ) with a $\mathrm{pH}$ of 6.0 to 6.5 . The drug and placebo solutions were administered intravenously in a randomized, double-blinded fashion.

\section{Experimental Protocol}

After baseline measurements, the cannulations of the heart and aorta were done. A cooling period of 60 minutes was carried out to attain an intracerebral temperature of $18^{\circ} \mathrm{C}$. After 45 minutes of cooling, the first infusion of the drug (FDP $500 \mathrm{mg} / \mathrm{kg}$ ) or placebo was started, and it was administered during a 15 -minute period. The ascending aorta was crossclamped just distal to the aortic cannula, cardiac arrest was induced by injecting potassium chloride $(3 \mathrm{~g})$ through the aortic cannula, and a 75-minute period of HCA was started. Topical cardiac cooling with ice slush was begun and maintained throughout the HCA period, and the intracerebral temperature was maintained at a level of $18^{\circ} \mathrm{C}$ with ice packs placed over the head. After 75-minutes of HCA, reperfusion and rewarming were commenced, and at the same time a second infusion of the drug (FDP $500 \mathrm{mg} / \mathrm{kg}$ ) or placebo was started, and it was administered during a 30 -minute period. The animals were rewarmed to a core temperature of $37^{\circ} \mathrm{C}$ during 60 minutes of reperfusion, and this temperature was maintained until the end of the experiment. The temperatures were regulated with heat-exchanger mattress, heating lamps, and ice packs.

During rewarming, the left ventricular sump cannula was removed, and furosemide (40 mg), mannitol (15 g), methylprednisolone $(80 \mathrm{mg}$ ), lidocaine $(40-160 \mathrm{mg})$, and calcium glubionate (1375 mg) were administered. After weaning from CPB, cardiac support was provided with dopamine. The animals were kept under anesthesia with isoflurane. They were ventilated with $100 \%$ oxygen until 2 hours after the start of rewarming, and after that with $50 \%$ oxygen until the extubation which occurred 8 hours after the start of rewarming. After extubation the animals were moved to a recovery room.

During the experiment, hemodynamic and metabolic measurements were recorded continuously or at baseline, at the end of cooling (immediately before institution of HCA), and 30 minutes, 2 hours, 4 hours, and 8 hours after the start of rewarming. Pulse rate, systemic and pulmonary arterial pressures, central venous pressure, pulmonary capillary wedge pressure, cardiac output, intracranial pressure, intracerebral tissue $\mathrm{Po}_{2}$, and temperatures were monitored. Arterial and venous $\mathrm{pH}$ values, $\mathrm{PaO}_{2}, \mathrm{PCO}_{2}$, oxygen saturation, oxygen concentration, hematocrit, hemoglobin, sodium, potassium, and glucose were measured with the Ciba-Corning 288 Blood Gas System (Ciba-Corning Diagnostic Corp, Medfield, Mass). Lactate was measured with the YSI 1500 analyzer (YSI Incorporated, Yellow Springs, Ohio). Leukocyte differential counts were performed with the Cell-Dyn analyzer (Abbot, Santa Clara, Calif). Ionized calcium and phosphate were measured with the Cobas Integra (Roche Diagnostics Division, Basel, Switzerland). Pyruvate was measured with the Hitachi 911 (Roche Diagnostics GmbH, Mannheim, Germany). Creatine kinase $(\mathrm{CK})$ and its isoenzymes (CK-MM, CK-MB, and CK-BB) were measured with the Hydrasys LC-electrophoresis Hyrys-densitometer (SEBIA France, Issy-les-Moulineaux, France).

\section{Postoperative Evaluation}

After the operation all the animals were evaluated on daily basis with a species-specific quantitative behavioral score by an experienced observer who was blinded to the study group. The assessment quantified mental status ( 0 , comatose; 1 , stuporous; 2 , depressed; 3, normal), appetite ( 0 , refuses liquids; 1 , refuses solids; 2 , decreased; 3 , normal), and motor function ( 0 , unable to stand; 1 , unable to walk; 2 , unsteady gait; 3 , normal). Numeric summing of these functions provided a final score, with a maximum score of 9 reflecting apparently normal neurologic function and lower values indicating substantial brain damage.

\section{Perfusion Fixation}

Each surviving animal was electively killed on the seventh postoperative day. Immediately after intravenous injection of pentobarbital $(60 \mathrm{mg} / \mathrm{kg})$ and heparin $(500 \mathrm{IU} / \mathrm{kg})$, the thoracic cavity was opened, and the descending thoracic aorta was clamped. Ringer solution $(1 \mathrm{~L})$ was infused through the ascending thoracic aorta through the upper body, and blood was suctioned from the superior vena cava until the perfusate was clear of blood. Then $10 \%$ formalin solution (1 L during 15 minutes) was perfused through the brain in the same manner to accomplish a perfusion fixation. Immediately thereafter the entire brain was removed, weighed, and immersed in $10 \%$ neutral formalin. The same method of fixation procedure was carried out in those animals that died before the seventh postoperative day.

\section{Histopathologic Analysis}

The brain was allowed to fix in formalin for 1 week en bloc. Thereafter, 3-mm thick coronal samples were sliced from the left frontal lobe, thalamus (including the adjacent cortex), and hippocampus (including the adjacent brainstem and temporal cortex), and sagittal samples were sliced from the posterior brainstem (medulla oblongata and pons) and cerebellum. The specimens 


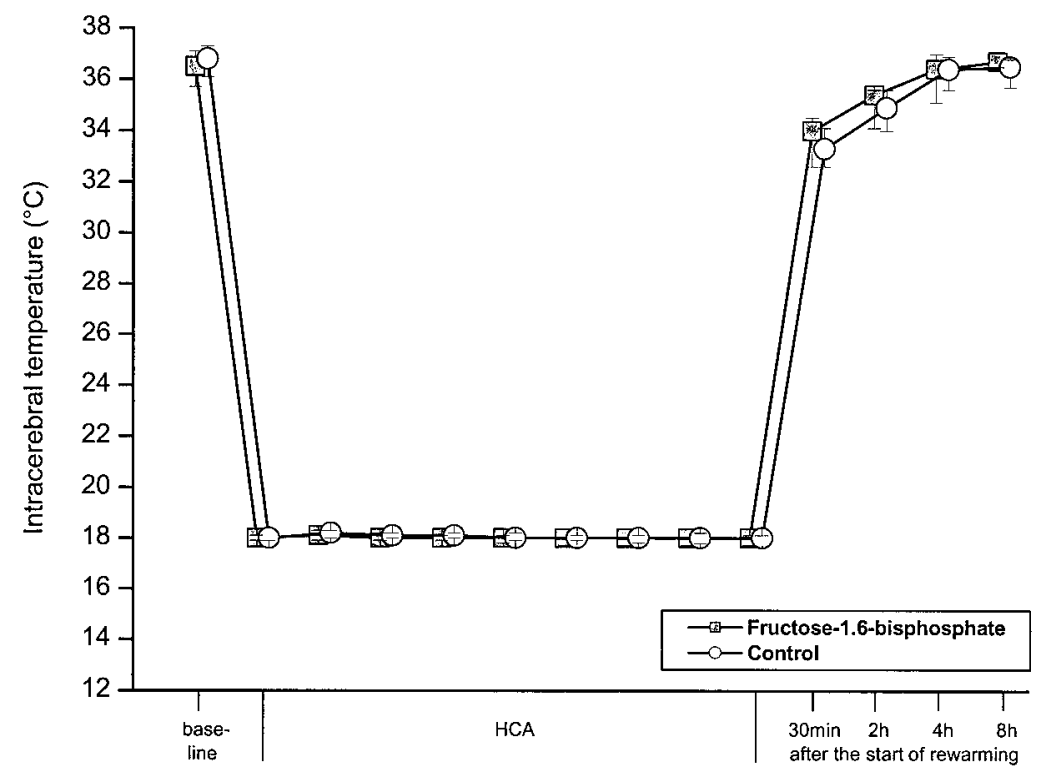

Figure 1. Intracerebral temperatures in pigs during experimental protocol in FDP (squares) and control (circles) groups. Data points represent medians; error bars represent interquartile ranges (25th-75th percentile).

were fixed in fresh formalin for another week. After fixation, the samples were processed as follows: rinsing in water for 20 minutes and immersion in $70 \%$ ethanol for 2 hours, immersion in $94 \%$ ethanol for 4 hours, and immersion in absolute ethanol for 9 hours. The specimens were then kept for 1 hour in absolute ethanolxylene mixture and 4 hours in xylene and embedded in warm paraffin for 6 hours. The specimens were sectioned at $6 \mu \mathrm{m}$ and stained with hematoxylin and eosin. The sections of the brain specimens of each animal were screened by an experienced senior pathologist (J.H.), who was unaware of the experimental design and of the identity and fate of each individual animal. Each section was carefully examined for the presence or absence of any ischemic or other kinds of tissue damage.

The signs of injury were scored as follows: 1, dark or eosinophilic neurons or cerebellar Purkinje cells; 2, moderate edema; and 3 , severe edema or infarct foci (local necrosis). A total histopathologic score was calculated by summing the scores of each specific brain area (cortex, thalamus, hippocampus, posterior brainstem, and cerebellum) to allow semiquantitative comparisons among the animals. The histopathologic score in this study was determined according to a commentary to the article by Rimpiläinen and colleagues. ${ }^{10}$

\section{Statistical Analysis}

Statistical analysis was performed with SPSS software (SPSS version 10.0; SPSS Inc, Chicago, Ill). Values are expressed as the median with interquartile ranges (25th-75th percentile). Differences in survival outcomes in the study groups were evaluated with the Fisher exact test. Differences between the study groups were determined with the $t$ test or the Mann-Whitney test. Variance analysis of repeated measurements was used, and the results of the tests of between-subjects effects and of interactions between time versus baseline and other intervals in these two groups were reported.

\section{Results}

\section{Comparability of the Groups}

The median weights of the pigs were $30.5 \mathrm{~kg}$ (interquartile range $29.4-31.6 \mathrm{~kg}$ ) in the FDP group and $28.6 \mathrm{~kg}$ (interquartile range $27.0-30.4 \mathrm{~kg})$ in the control group $(P=.03)$. However, there was no statistically significant difference in weight between the pigs that died before the seventh postoperative day and those that survived (median $28.1 \mathrm{~kg}$ vs $30.2 \mathrm{~kg}, P=.11$ ). The median CPB cooling times were 61.0 minutes (interquartile range 60.0-60.3 minutes) in the FDP group and 61.0 minutes (interquartile range 60.3-62.0 minutes) in the control group $(P=.84)$. The median $\mathrm{CPB}$ rewarming times were 63.5 minutes (interquartile range 61.3-68.3 minutes) in the FDP group and 63.0 minutes (interquartile range 62.3-69.3 minutes) in the control group $(P=.89)$. The median total CPB times were 126.0 minutes (interquartile range 123.5-134.3 minutes) in the FDP group and 124.5 minutes (interquartile range 123.3-129.8 minutes) in the control group $(P=.67)$. During the experiment the intracerebral temperatures did not differ between the study groups (Figure 1).

\section{Mortality and Behavioral Outcome}

The 7-day survivals were $83.3 \%$ in the FDP group and $41.7 \%$ in the control group $(P=.09)$. The postoperative behavioral scores of the animals are presented in Figure 2. $P$ values for comparisons between the groups on each postoperative day (from the first through the seventh) in surviving animals were as follows: $P=.001, P=.27, P=$ $.03, P=.05, P=.09, P=.004$, and $P=.004$, respectively. The sums of behavioral score from each postoperative day 

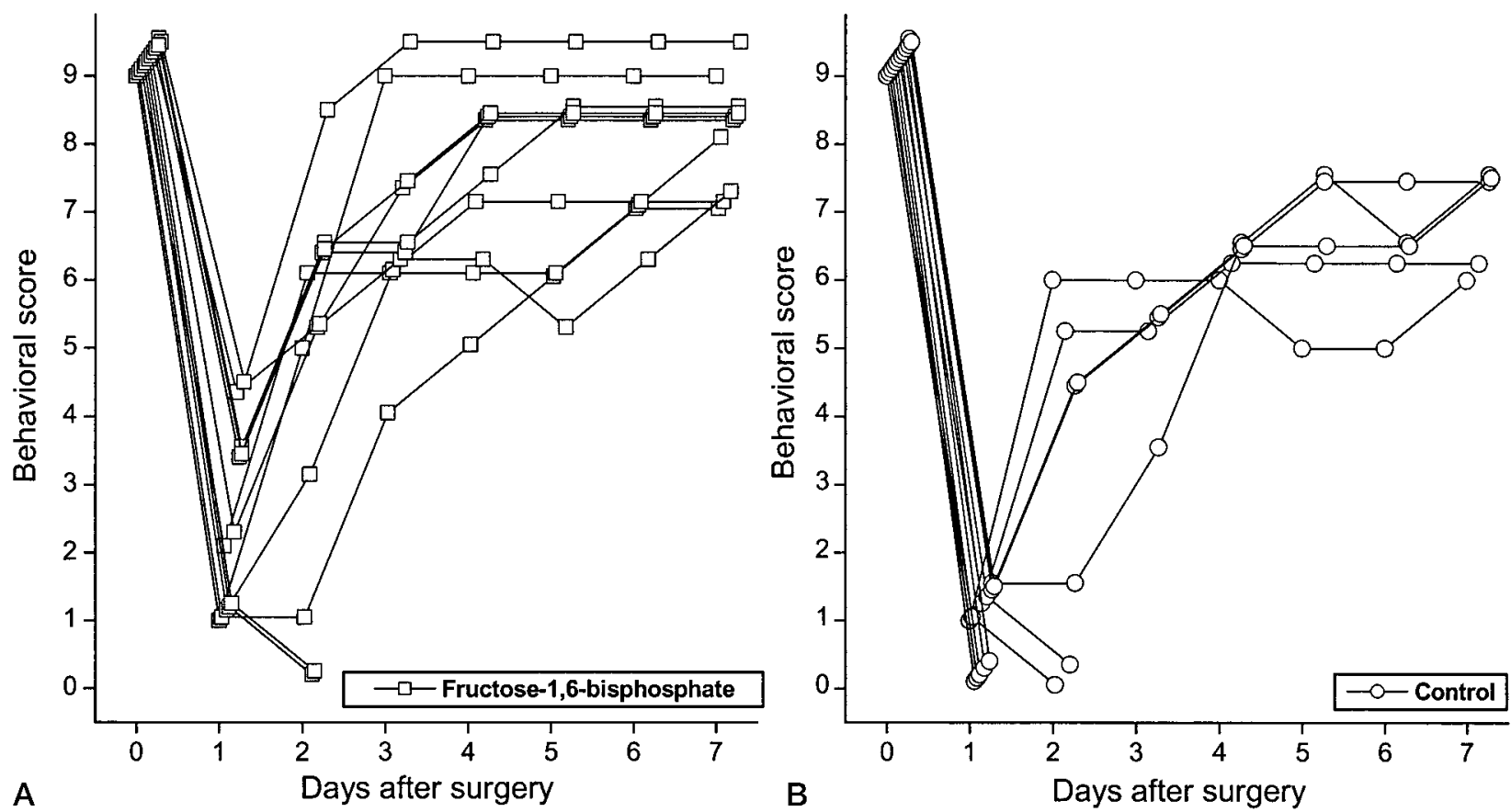

Figure 2. Daily scores from each animal in FDP (A) and control (B) groups indicating behavioral recovery after 75 minutes of HCA. Score of 9 indicates essentially complete recovery.

in animals surviving at 7 days were significantly different between the groups (44.4 in the FDP group and 34.6 in the control group, $P=.01$ ).

\section{Hemodynamic and Metabolic Data}

Hemodynamic and metabolic data are presented in Tables 1 and 2 and in Figure 3. There were no significant differences between the study groups in terms of cardiac indices, mean arterial pressures, and hemoglobin levels. After the administration of FDP, there was a significant increase in serum phosphate level $(P<.001)$ and a significant decrease in serum ionized calcium level $(P<.001)$. The drug also increased the serum sodium level so that the osmolarity was significantly higher in the FDP group $(P<.001)$. This also led to an increased diuresis rate and a better fluid balance in the FDP group during the postoperative period $(P=.03)$. The animals in the FDP group had significantly higher blood glucose levels at the 2-hour interval after the start of rewarming $(P=.03)$. Serum potassium was significantly lower in the FDP group at extubation $(P=.007)$, possibly as a result of increased diuresis. Vascular resistance was lower in the FDP group throughout the experiment $(P=$ $.05)$.

There where no statistically significant differences between the study groups in terms of blood pyruvate levels or blood lactate-pyruvate ratio. However, blood lactate was significantly lower in the FDP group at the end of cooling $(P=.03)$.

The administration of the drug caused mild and shortlasting decreases in arterial and venous $\mathrm{pH}$ levels, which reached statistical significance at the end of cooling period ( $P=.02$ and $P=.04$, respectively). Also, $\mathrm{PaCO}_{2}$ was higher in the FDP group at the end of cooling. Mixed venous $\mathrm{Po}_{2}$ and oxygen saturation were significantly lower $(P<.001)$ and oxygen extraction was higher $(P<.001)$ in the FDP group at the 2-hour interval after the start of rewarming, at the same time that mean arterial pressure and cardiac index tended to be lower in this group.

Venous total CK and CK-MM levels were significantly lower in the FDP group at extubation $(P=.04$ and $P=.05$, respectively). Venous CK-BB levels were higher in the FDP group at the end of cooling $(P=.009)$. Venous CK-MB levels were lower in the FDP group throughout the postoperative period. This difference was statistically significant at 30-minute interval after the start of rewarming $(P=.001)$.

\section{Intracranial Measurements}

Intracranial measurement data are presented in Figure 4. Brain glucose tended to be higher in the FDP group during the first hours after the start of rewarming. Brain lactate also tended to be higher in the FDP group from the 90-minute interval until the 4-hour interval after the start of rewarming. 
TABLE 1. Experimental data

\begin{tabular}{|c|c|c|c|c|c|c|c|}
\hline & \multirow[b]{2}{*}{ Baseline } & \multirow[b]{2}{*}{ End of cooling } & \multicolumn{4}{|c|}{ After start of rewarming } & \multirow[b]{2}{*}{$P$ value } \\
\hline & & & $30 \mathrm{~min}$ & $2 \mathrm{~h}$ & $4 \mathrm{~h}$ & 8 h & \\
\hline \multicolumn{8}{|c|}{ Mean arterial pressure $(\mathrm{mm} \mathrm{Hg})$} \\
\hline FDP & $73(70-81)$ & $52(50-55)$ & $60(54-69)$ & $62(56-66)$ & $60(58-66)$ & $64(54-70)$ & \multirow[t]{2}{*}{.27} \\
\hline Control & $77(69-85)$ & $56(53-65)$ & $61(56-65)$ & $65(61-69)$ & $66(59-71)$ & $62(58-67)$ & \\
\hline \multicolumn{8}{|c|}{ Cardiac index $\left(\mathrm{L} /\left[\mathrm{min} \cdot \mathrm{m}^{2}\right]\right)$} \\
\hline FDP & $4.2(3.9-4.4)$ & $3.0(2.7-3.5)$ & $3.4(3.1-3.9)$ & $4.1(3.9-5.2)$ & $4.1(3.8-4.5)$ & $3.9(3.6-4.1)$ & \multirow[t]{2}{*}{.99} \\
\hline Control & $4.0(3.3-4.7)$ & $3.1(3.0-3.4)$ & $3.5(3.1-3.6)$ & $4.6(4.4-5.5)$ & $4.3(4.1-4.7)$ & $3.9(3.1-3.9)$ & \\
\hline \multicolumn{8}{|c|}{ Dopamine administration (mg/h) } \\
\hline FDP & - & - & - & $6.3(3.1-7.8)$ & $5.8(3.3-8.4)$ & $5.8(4.0-8.4)$ & \multirow[t]{2}{*}{-} \\
\hline Control & - & - & - & $4.6(4.0-5.8)$ & $4.5(2.3-5.9)$ & $5.3(3.3-7.8)$ & \\
\hline \multicolumn{8}{|c|}{ Hemoglobin $(g / L)$} \\
\hline FDP & $99(94-104)$ & $69(65-71)$ & $74(68-81)$ & $89(76-105)$ & $83(77-100)$ & $87(74-92)$ & \multirow[t]{2}{*}{.40} \\
\hline Control & $98(89-101)$ & $68(61-74)$ & $74(63-84)$ & $85(75-91)$ & $86(75-92)$ & $85(73-90)$ & \\
\hline \multicolumn{8}{|c|}{ Vascular resistance $\left(\right.$ dyne $\left.\cdot \mathrm{s} \cdot \mathrm{cm}^{-5}\right)$} \\
\hline FDP & 1605 & 1563 & 1565 & 1297 & 1340 & 1486 & \multirow[t]{2}{*}{.05} \\
\hline Control & 1668 & 1674 & 1623 & 1296 & 1386 & 1670 & \\
\hline \multicolumn{8}{|c|}{ Fluid balance $(\mathrm{mL})$} \\
\hline FDP & $200(0-300)$ & $2000(1700-2500)$ & $1900(1300-2200) \dagger$ & $1600(1200-2200) \dagger$ & $1400(700-1700) \dagger$ & $1100(800-1400) \dagger$ & \multirow[t]{2}{*}{.03} \\
\hline Control & $100(0-300)$ & $2000(1800-2300)$ & $2200(2100-2400) \dagger$ & $2200(1700-3100) \dagger$ & $1900(1400-2400) \dagger$ & $1500(1000-2700) \dagger$ & \\
\hline \multicolumn{8}{|c|}{ Venous total CK (U/L) } \\
\hline FDP & $1216(918-2596)$ & 1666 (1283-2338) & 3257 (1949-4587) & 7278 (4602-9370) & 8484 (5912-10693) & 8107 (6516-12,518)‡ & \multirow[t]{2}{*}{62} \\
\hline Control & $1783(1583-4229)$ & $2640(1531-4941)$ & $3987(2346-5986)$ & 8174 (5316-11744) & $11,450(8348-15,351)$ & 12,129 (8102-18,215‡ & \\
\hline \multicolumn{8}{|c|}{ Venous CK-MM (U/L) } \\
\hline FDP & $884(595-2266)$ & 1449 (1056-2132) & 3019 (1719-4294) & $6745(4168-8765)$ & $7725(5382-10,118)$ & 7606 (6136-11,927)‡ & \multirow[t]{2}{*}{.63} \\
\hline Control & 1473 (1377-3979) & $2470(1389-4798)$ & 3554 (1967-5626) & $7528(4712-11,253)$ & $10877(7992-14,542)$ & $11,341(7415-15,355) \ddagger$ & \\
\hline \multicolumn{8}{|c|}{ Venous CK-MB (U/L) } \\
\hline FDP & $25(19-33)$ & $33(28-47)$ & $42(32-56) \S$ & $81(65-161)$ & $114(66-201)$ & $103(68-200)$ & \multirow[t]{2}{*}{.11} \\
\hline Control & $35(27-60)$ & $34(27-56)$ & $78(61-125) \S$ & $114(71-146)$ & $154(134-224)$ & $163(117-255)$ & \\
\hline \multicolumn{8}{|c|}{ Venous CK-BB (U/L) } \\
\hline FDP & $247(137-291)$ & $145(112-164) \S$ & $158(134-172)$ & $368(303-422)$ & $404(293-525)$ & $289(218-439)$ & \multirow[t]{2}{*}{.34} \\
\hline Control & $154(137-240)$ & $100(73-119) \S$ & $165(135-228)$ & $289(193-379)$ & $331(191-402)$ & $312(162-417)$ & \\
\hline \multicolumn{8}{|c|}{ Brain tissue oxygen pressure $(\mathrm{mm} \mathrm{Hg})$} \\
\hline FDP & $27(20-29)$ & $38(18-50) \dagger$ & $21(16-25)$ & $22(18-43)$ & $20(15-31)$ & $24(18-45)$ & \multirow[t]{2}{*}{.85} \\
\hline Control & $23(17-31)$ & $39(14-89) \dagger$ & $29(21-56)$ & $29(24-38)$ & $20(15-28)$ & $25(18-37)$ & \\
\hline
\end{tabular}

Values are shown as medians with interquartile ranges (25th-75th percentile). $P$ values between groups are according to the tests of between-subjects effects.

*Fluid balance represents fluids given intravenously minus cumulative diuresis.

$\dagger P<.05$ interaction between time versus baseline and other intervals in the study groups.

$\ddagger P<.05$ FDP group versus control group.

$\S P<.01$ FDP group versus control group.

Brain pyruvate levels were significantly higher in the FDP group at the end of the rewarming period $(P=.01)$ and tended to be higher in this group also from the 2-hour interval after the start of rewarming until extubation. Brain lactate-glucose ratio showed no differences between the study groups, whereas brain lactate-pyruvate ratio was significantly lower in the FDP group at the end of rewarming (43.4 in the FDP group vs 59.2 in the control group, $P=$ .008). Brain glycerol tended to be lower in the FDP group during the first postoperative hours, whereas brain glutamate levels were similar between the groups. The maximum values of the brain microdialysis measurements showed the only difference between the groups in lactate levels, which were slightly but not significantly higher in the FDP group
(10.0 $\mathrm{mmol} / \mathrm{L}$ in the FDP group vs $7.7 \mathrm{mmol} / \mathrm{L}$ in the control group, $P=.08$ ).

Brain tissue $\mathrm{Po}_{2}$ did not differ between the groups at any time point except at the end of cooling, when it was lower in the FDP group $(P=.04$; Table 1$)$. At that point cerebral perfusion pressure was slightly but not significantly lower in that group (44 mm Hg in the FDP group vs $48 \mathrm{~mm} \mathrm{Hg}$ in the control group, $P=.23$ ). Intracranial pressure levels were significantly lower in the FDP group during rewarming $(P=.01$; Figure 4$)$.

\section{Electroencephalographic Findings}

There were no statistically significant differences between the study groups in the EEG burst-suppression ratios at 
TABLE 2. Metabolic data

\begin{tabular}{|c|c|c|c|c|c|c|c|}
\hline & \multirow[b]{2}{*}{ Baseline } & \multirow[b]{2}{*}{ End of cooling } & \multicolumn{4}{|c|}{ After start of rewarming } & \multirow[b]{2}{*}{$P$ value } \\
\hline & & & $30 \mathrm{~min}$ & $2 \mathrm{~h}$ & $4 \mathrm{~h}$ & $8 \mathrm{~h}$ & \\
\hline \multicolumn{8}{|l|}{ Arterial pH } \\
\hline FDP & 7.50 (7.49-7.53) & $7.37(7.33-7.45)^{*}$ & 7.36 (7.32-7.42) & 7.45 (7.43-7.48) & 7.52 (7.50-7.54) & 7.55 (7.52-7.57) & \multirow[t]{2}{*}{.47} \\
\hline Control & $7.52(7.48-7.56)$ & $7.45(7.43-7.48)^{*}$ & 7.39 (7.32-7.42) & $7.44(7.39-7.47)$ & $7.50(7.48-7.54)$ & $7.53(7.50-7.54)$ & \\
\hline \multicolumn{8}{|l|}{ Venous pH } \\
\hline FDP & 7.46 (7.44-7.49) & $7.35(7.32-7.42)^{*}$ & 7.33 (7.27-7.37) & 7.40 (7.39-7.43) & 7.48 (7.47-7.49) & $7.50(7.46-7.51)$ & \multirow[t]{2}{*}{.74} \\
\hline Control & $7.48(7.42-7.51)$ & $7.41(7.38-7.43)^{*}$ & $7.31(7.25-7.36)$ & $7.40(7.36-7.42)$ & 7.46 (7.44-7.48) & $7.48(7.45-7.49)$ & \\
\hline \multicolumn{8}{|c|}{$\mathrm{PaCO}_{2}(\mathrm{kPa})$} \\
\hline FDP & $5.1(5.0-5.2)$ & $5.8(4.9-6.4)$ & $4.7(4.4-4.9)$ & $5.4(5.1-5.7)$ & $5.3(5.2-5.5)$ & $5.3(5.0-5.7)$ & \multirow[t]{2}{*}{.03} \\
\hline Control & $5.1(4.8-5.4)$ & $5.2(4.4-5.5)$ & $4.7(4.4-5.0)$ & $5.3(5.0-5.6)$ & $5.1(4.9-5.4)$ & $5.3(5.0-5.5)$ & \\
\hline \multicolumn{8}{|l|}{$\mathrm{PvCO}_{2}(\mathrm{kPa})$} \\
\hline FDP & $6.1(5.8-6.3)$ & $6.2(5.4-6.8)$ & $5.7(5.2-6.2)$ & $6.5(6.3-6.8)$ & $6.3(6.1-6.7)$ & $6.4(6.2-6.8)$ & \multirow[t]{2}{*}{.73} \\
\hline Control & $6.1(6.0-6.5)$ & $5.9(5.3-6.2)$ & $5.8(5.3-6.5)$ & $6.5(6.1-6.7)$ & $6.3(6.1-6.6)$ & $6.5(6.2-6.8)$ & \\
\hline \multicolumn{8}{|l|}{$\mathrm{PaO}_{2}(\mathrm{kPa})$} \\
\hline FDP & $30.1(27.0-36.1)$ & $123(108-127)$ & $54.9(51.9-72.8)$ & $73.3(64.2-79.7)$ & $30.4(26.8-36.1)$ & $31.6(27.4-37.3)$ & \multirow[t]{2}{*}{.44} \\
\hline Control & $37.2(32.3-39.5)$ & $114(110-123)$ & $63.0(58.2-66.2)$ & $75.2(66.4-80.5)$ & $30.4(28.9-34.0)$ & $30.2(27.9-34.3)$ & \\
\hline \multicolumn{8}{|l|}{$\mathrm{PvO}_{2}(\mathrm{kPa})$} \\
\hline FDP & $6.3(5.8-6.6)$ & $49.1(41.5-53.3)$ & $6.9(6.3-7.2)^{*}$ & $6.2(5.9-6.5) \dagger$ & $5.3(4.8-5.4)$ & $4.7(4.3-5.1)$ & \multirow[t]{2}{*}{.88} \\
\hline Control & $5.9(5.5-6.3)$ & $52.6(38.7-56.4)$ & $6.9(6.4-7.5)^{*}$ & $7.2(6.5-7.6) \dagger$ & $5.3(4.9-5.4)$ & $4.6(4.5-4.9)$ & \\
\hline \multicolumn{8}{|c|}{ Mixed venous oxygen saturation (\%) } \\
\hline FDP & $83.7(81.6-87.3)$ & $99.8(99.7-99.8)$ & $84.1(82.0-85.7)^{*}$ & $82.0(78.6-84.4) \dagger$ & $77.1(71.1-79.8)$ & $71.9(66.6-74.8)$ & \multirow[t]{2}{*}{.99} \\
\hline Control & $83.0(77.7-84.9)$ & 99.8 (99.7-99.8) & $82.9(80.4-86.1)^{*}$ & $87.0(84.9-88.4) \dagger$ & $76.6(73.3-77.4)$ & $71.0(67.1-71.9)$ & \\
\hline \multicolumn{8}{|c|}{ Oxygen extraction $(\mathrm{mL} / \mathrm{dL})$} \\
\hline FDP & $2.7(2.2-3.0)$ & $1.6(1.4-1.9)^{*}$ & $2.9(2.5-3.5)$ & $3.6(2.9-4.3) \dagger$ & $3.3(2.7-3.9)$ & $3.8(3.2-4.7)$ & \multirow[t]{2}{*}{.55} \\
\hline Control & $3.0(2.7-3.4)$ & $1.5(1.4-1.6)^{*}$ & $2.7(2.6-3.2)$ & $3.0(2.9-3.4) \dagger$ & $3.3(3.0-3.8)$ & $4.0(3.6-4.3)$ & \\
\hline \multicolumn{8}{|c|}{ Venous glucose (mmol/L) } \\
\hline FDP & $6.0(5.3-7.4)$ & $6.0(5.7-6.9)$ & $13.4(11.7-15.4)$ & $10.4(8.9-12.6)^{*}$ & $9.0(8.0-10.3)$ & $7.1(6.7-8.5)$ & \multirow[t]{2}{*}{.38} \\
\hline Control & $5.9(5.6-6.5)$ & $7.0(5.1-7.5)$ & $13.5(12.1-14.9)$ & $8.8(7.6-9.9)^{*}$ & $8.0(7.3-9.1)$ & $7.4(6.9-8.0)$ & \\
\hline \multicolumn{8}{|c|}{ Venous lactate (mmol/L) } \\
\hline FDP & $1.0(0.8-1.0)$ & $1.3(1.1-1.6)^{*}$ & $4.4(4.2-5.0)$ & $3.1(2.8-3.3)$ & $1.4(1.2-1.7)$ & $1.0(0.9-1.2)$ & \multirow[t]{2}{*}{.68} \\
\hline Control & $1.0(0.7-1.3)$ & $1.7(1.5-2.1)^{*}$ & $4.8(3.9-5.6)$ & $3.0(2.5-4.3)$ & $1.2(1.1-1.5)$ & $1.0(0.8-1.1)$ & \\
\hline \multicolumn{8}{|c|}{ Venous potassium (mmol/L) } \\
\hline FDP & $3.6(3.5-3.7)$ & $3.2(3.0-3.4)^{*}$ & $4.8(4.6-5.0)$ & $5.3(4.5-6.9)$ & $4.4(4.2-4.8)$ & $4.3(4.0-4.7) \dagger$ & \multirow[t]{2}{*}{$>.99$} \\
\hline Control & $3.6(3.4-3.8)$ & $3.0(2.8-3.2)^{*}$ & $5.1(4.7-5.4)$ & $4.9(4.4-5.3)$ & $4.9(4.7-5.1)$ & $4.9(4.6-5.6) \dagger$ & \\
\hline
\end{tabular}

Values are shown as medians with interquartile ranges (25th-75th percentile). $P$ values between groups are according to the tests of between-subjects effects.

${ }^{*} P<.05$ interaction between time versus baseline and other intervals in the study groups.

$\dagger P<.01$ interaction between time versus baseline and other intervals in the study groups.

baseline or after the start of reperfusion. However, the animals in the FDP group tended to have somewhat quicker recovery of EEG to normal activity level during the postoperative period (Figure 5).

\section{Histopathologic Data}

The brain histopathologic scores are presented in Table 3 and in Figure 6. The total histopathologic score among the animals of the FDP group was significantly lower than that among the control animals (3.42 vs 6.08 , respectively, $P=$ $.04)$. Also, the scores from the thalamus $(P=.01)$ and the hippocampus $(P=.04)$ showed statistically significant differences between the groups, with the FDP group having lower scores in these brain regions. The total score from dark or eosinophilic neurons or cerebellar Purkinje cells from different brain regions (cortex, thalamus, hippocam- pus, posterior brainstem, and cerebellum) and this score from the thalamus alone were lower in the FDP group $(P=$ .02 and $P=.03$, respectively), as was the edema score in the cortex $(P=.04)$.

\section{Discussion}

During the last few years we have tested in this surviving model of HCA several strategies aimed at attenuating the brain injury that occurs during the reperfusion phase. ${ }^{11-14}$ The use of FDP in this study was predicated on the need to develop a protective strategy also able to cover phases of the ischemic injury process other than reperfusion. Indeed, FDP seems to provide metabolic support to the brain during the ischemic phase, with beneficial effects extending to the reperfusion period. ${ }^{5-7}$ Of great importance is the fact that FDP also can provide metabolic support to other important 

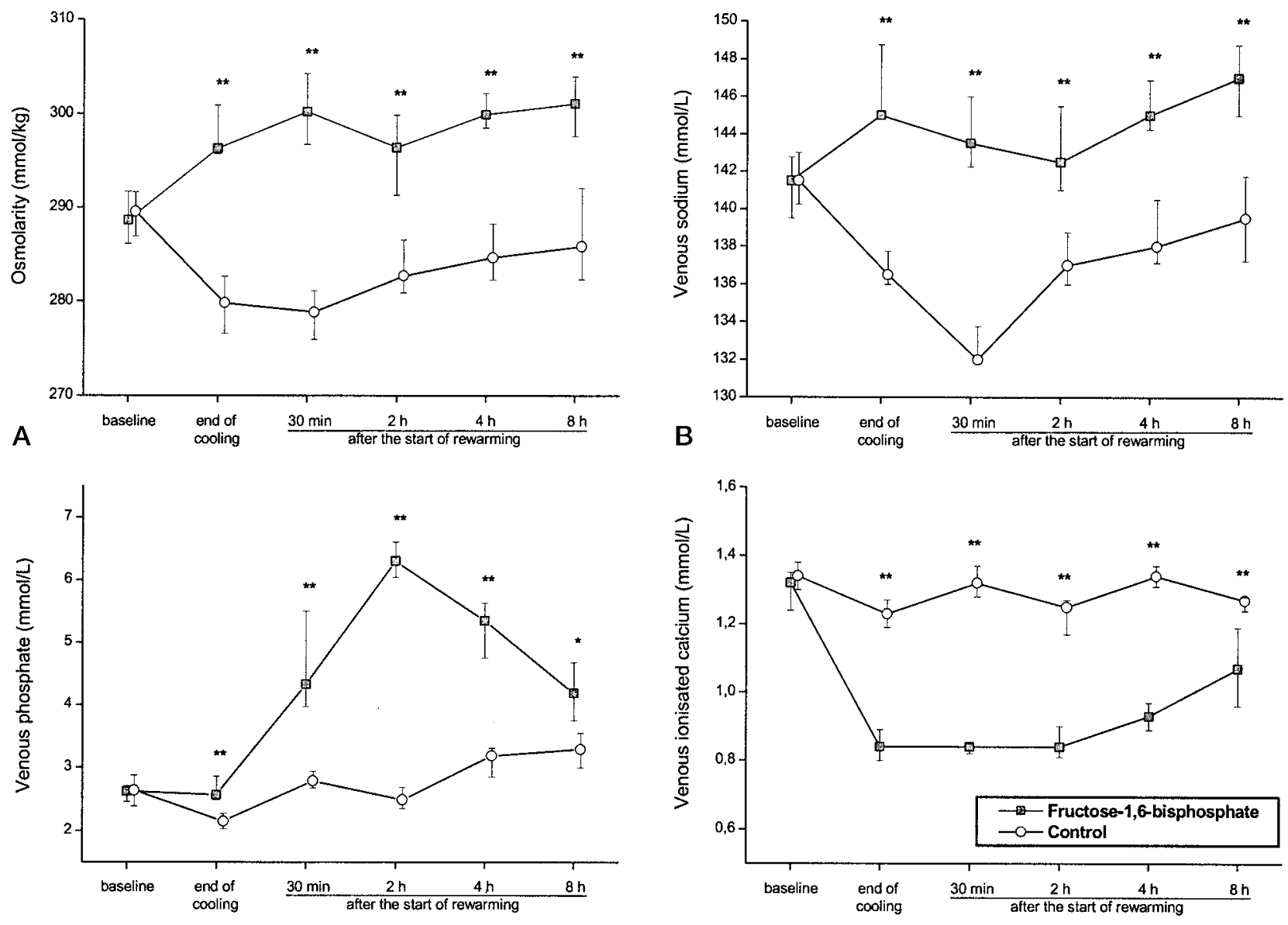

C

DATA RECORDING POINTS

D

DATA RECORDING POINTS

Figure 3. Electrolytes and osmolarity in FDP (squares) and control (circles) groups. Data points represent medians; error bars represent interquartile ranges (25th-75th percentile). Asterisk indicates $\boldsymbol{P}<.05$ for interaction between time versus baseline and other intervals in study groups; double asterisk indicates $\boldsymbol{P}<.01$ for interaction between time versus baseline and other intervals in study groups. A, Osmolarity; B, venous sodium; C, venous phosphate; D, venous ionized calcium.

organs, such as the heart, ${ }^{2-4}$ and this ultimately has an impact on the outcome after such a severe period of global ischemia.

The mechanism of action of FDP is still unclear. In addition to its function as a regulator of glycolysis through stimulation of phosphofructokinase, FDP may affect glycolysis by acting as an alternative metabolic substrate. ${ }^{4}$ It may bypass the reaction involving phosphofructokinase and increase ATP production. Thus FDP administration could preserve cellular energy stores during periods of hypoxia and reestablish cellular energy production after a period of hypoxia. This speculation is supported by the results of this study, which showed increased brain glucose and pyruvate levels and a higher brain pyruvate-lactate ratio during the reperfusion period in the FDP-treated animals than in the control animals.

The glycolysis-related mode of action assumes that ex- ogenous FDP enters the cell. FDP traditionally has been thought to be unable to cross the cell membrane. However, there is some indirect evidence supporting the ability of FDP to enter the cell. ${ }^{2,3,5,15}$ In addition to its stimulating effect on carbohydrate metabolism through its glycolysisrelated mode of action, ${ }^{16}$ other interesting mechanisms of action have been suggested to be involved in the protective effects of FDP against ischemic cell injury. FDP is able to regulate ion flow across cell membranes, and it has been shown to reduce the ischemia-induced intracellular accumulation of calcium ${ }^{1,2}$ and to enhance the uptake of potassium, thus reducing intracellular sodium concentration and cytotoxic edema. ${ }^{17}$ Moreover, FDP has been shown to inhibit the generation of oxygen free radicals by activated neutrophils during ischemia and reperfusion ${ }^{18}$ and to increase red blood cell deformability, thus decreasing blood viscosity. ${ }^{19}$ FDP has also been shown to protect cerebrovascular endo- 

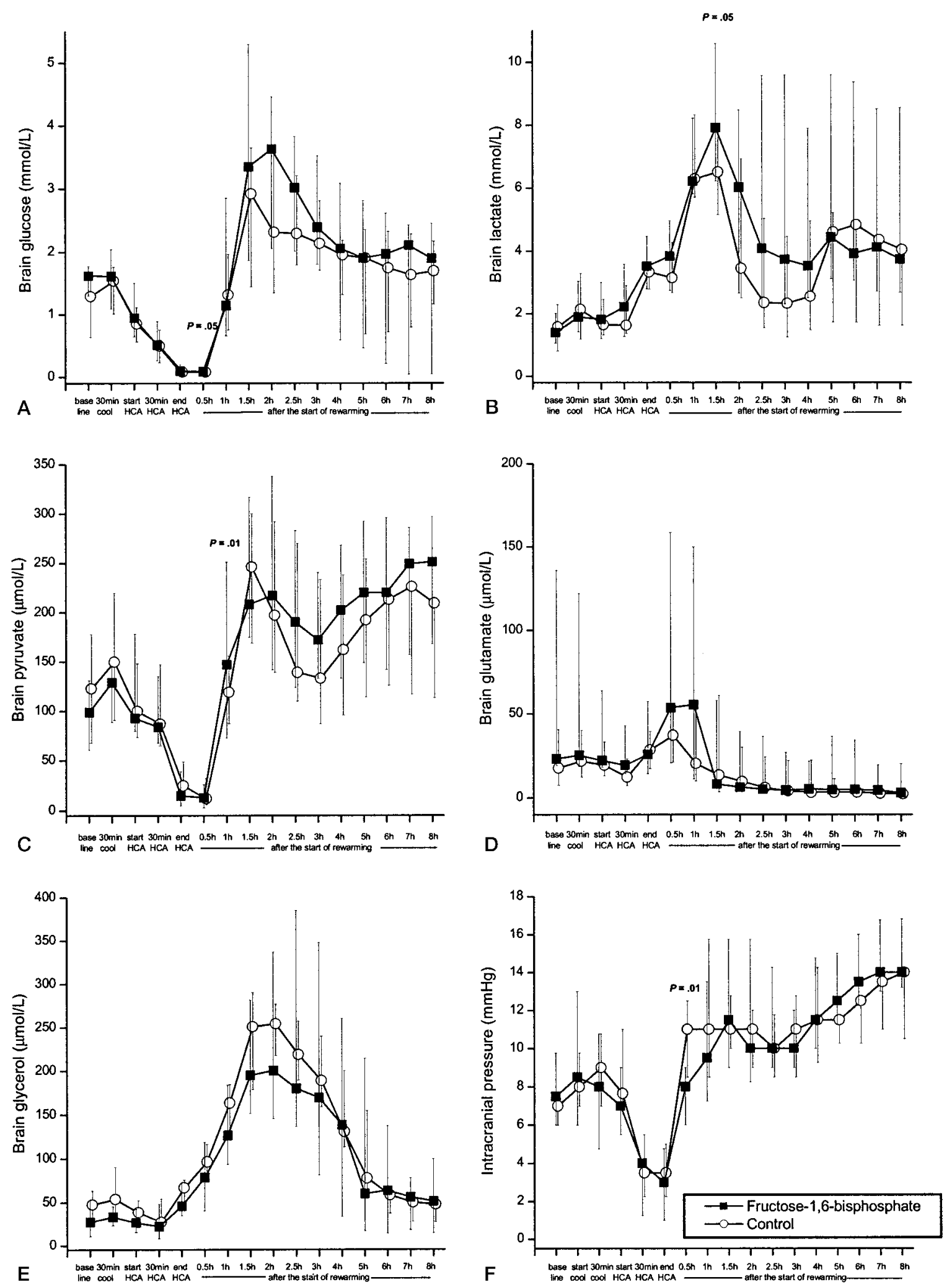

Figure 4. Results of brain microdialysis and intracranial pressure measurements in FDP (squares) and control (circles) groups. Data points represent medians; error bars represent interquartile ranges (25th-75th percentile). $P$ values represent interaction between time versus baseline and other intervals in study groups. $A$, Brain glucose; B, brain lactate; C, brain pyruvate; D, brain glutamate; $E$, brain glycerol; $F$, intracranial pressure. 


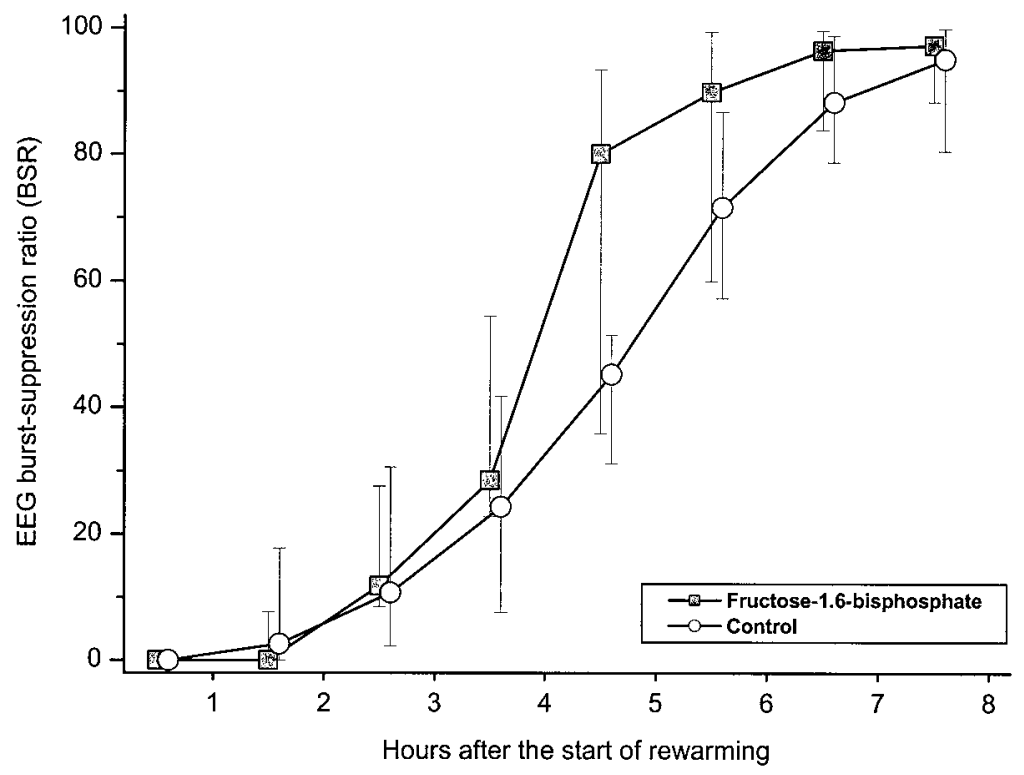

Figure 5. EEG burst recovery in pigs after 75 minutes of HCA in FDP (squares) and control (circles) groups. Burst-suppression ratio $=$ [EEG burst time/(EEG burst time + EEG suppression time $)] \times 100$. Data points represent medians; error bars represent interquartile ranges (25th-75th percentile).

thelial cells from hypoxic injury, ${ }^{20}$ thus possibly improving cerebral blood flow during reperfusion after an ischemic event.

Although a body of evidence strongly suggests a neuroprotective effect of FDP against brain ischemic injury, there have been studies in which FDP failed to ameliorate hypoxic ischemic injury. ${ }^{8,9}$ However, species and animal age differences as well as differences in timing of FDP administration and schedules of ischemia could explain these discrepancies.

In this study with a surviving porcine model of HCA, a distinct protective effect of FDP after global ischemia was observed in terms of survival, behavioral score, and histopathologic appearance. The overall survival could have been affected not only by preservation of neuronal function but also by protection of other vital organs, such as the heart and the lungs. However, significant differences between the groups in terms of cardiac index, mean arterial pressure, oxygen consumption, and oxygen delivery were not observed. This could be because of the calcium-chelating activity of FDP, which has been suggested to be one of the major mechanisms underlying its protective effect on myocardium exposed to a period of ischemia. Such a negative inotropic effect, in fact, is counterbalanced by a decrease in serum calcium and thus by a reduction of calcium overload after reperfusion, which is a well-known mechanism underlying ischemia-reperfusion cell injury. ${ }^{21,22}$ The relatively short-term postoperative monitoring of the latter parameters, however, precludes any conclusion regarding the effects of FDP after the first 8 hours from the end of HCA. On the other hand, FDP was associated with a decrease in postoperative serum CK-MB level, an observation that confirms the myocardial protective effects of this drug and possibly its effects also on other tissues exposed to prolonged systemic ischemia.

FDP was associated with an increase in blood $\mathrm{PCO}_{2}$ and also with increases in brain pyruvate and lactate concentrations, presumably as a result of increased energy metabolism through the glycolytic pathway. The administration of FDP led to a notable serum phosphate load, which resulted in a marked decrease in serum ionized calcium levels, probably as a result of the calcium-chelating effect of phosphate. This FDP-related effect has also been observed in other studies. 2,7,8,21 However, such a decrease in serum ionized calcium did not result in a major negative inotropic effect on myocardium, with cardiac index and mean arterial pressure of the FDP group similar to those observed in the placebo group. Peripheral vascular resistance was slightly decreased in the FDP group, probably because of FDP's calcium-chelating effect. This negative inotropic effect, as discussed previously, is associated with evident beneficial effects in terms of reduction of ischemia-reperfusion cell injury. ${ }^{21}$ The observation that calcium uptake in the brain correlates directly with plasma calcium levels ${ }^{22}$ suggests that such a calcium-chelating effect of the drug is likely to have lessened the detrimental effect of calcium influx into the neurons as well as into the myocardial cells.

The higher sodium content in the trisodium salt of FDP used in this study, as opposed to the physiologic level in the saline solution in the control group, led to significantly higher blood sodium levels and osmolarity and thus to a 
TABLE 3. Histopathologic scores

\begin{tabular}{|c|c|c|c|c|c|c|c|}
\hline Pig No. & $\begin{array}{l}\text { Survival } \\
\text { (d) }\end{array}$ & $\begin{array}{l}\text { Cortex } \\
\text { score }\end{array}$ & $\begin{array}{l}\text { Thalamus } \\
\text { score }\end{array}$ & $\begin{array}{l}\text { Hippocampus } \\
\text { score }\end{array}$ & $\begin{array}{l}\text { Posterior brainstem } \\
\text { score }\end{array}$ & $\begin{array}{l}\text { Cerebellum } \\
\text { score }\end{array}$ & $\begin{array}{l}\text { Total } \\
\text { score }\end{array}$ \\
\hline \multicolumn{8}{|l|}{ FDP } \\
\hline 1 & 7 & 0 & 0 & 0 & 0 & 0 & 0 \\
\hline 2 & 7 & 3 & 0 & 0 & 0 & 0 & 3 \\
\hline 3 & 7 & 4 & 0 & 0 & 0 & 1 & 5 \\
\hline 4 & 7 & 4 & 0 & 0 & 0 & 0 & 4 \\
\hline 5 & 2 & 1 & 0 & 0 & 0 & 0 & 1 \\
\hline 6 & 2 & 1 & 0 & 0 & 0 & 1 & 2 \\
\hline 7 & 7 & 4 & 2 & 1 & 1 & 1 & 9 \\
\hline 8 & 7 & 4 & 0 & 3 & 0 & 1 & 8 \\
\hline 9 & 7 & 1 & 0 & 1 & 0 & 1 & 3 \\
\hline 10 & 7 & 1 & 0 & 1 & 0 & 0 & 2 \\
\hline 11 & 7 & 1 & 0 & 0 & 0 & 0 & 1 \\
\hline 12 & 7 & 1 & 0 & 0 & 1 & 1 & 3 \\
\hline Mean & & 2.08 & $0.17^{*}$ & $0.50 \dagger$ & 0.17 & 0.5 & $3.42 \dagger$ \\
\hline \multicolumn{8}{|l|}{ Control } \\
\hline 1 & 7 & 1 & 0 & 0 & 0 & 1 & 2 \\
\hline 2 & 2 & 1 & 0 & 1 & 0 & 1 & 3 \\
\hline 3 & 1 & 2 & 2 & 1 & 1 & 1 & 7 \\
\hline 4 & 1 & 3 & 3 & 3 & 1 & 1 & 11 \\
\hline 5 & 1 & 1 & 1 & 0 & 0 & 0 & 2 \\
\hline 6 & 7 & 1 & 0 & 1 & 0 & 1 & 3 \\
\hline 7 & 1 & 3 & 2 & 3 & 1 & 0 & 9 \\
\hline 8 & 2 & 3 & 3 & 3 & 1 & 1 & 11 \\
\hline 9 & 1 & 3 & 3 & 2 & 0 & 1 & 9 \\
\hline 10 & 7 & 4 & 0 & 1 & 0 & 1 & 6 \\
\hline 11 & 7 & 4 & 0 & 0 & 0 & 1 & 5 \\
\hline 12 & 7 & 1 & 3 & 1 & 0 & 0 & 5 \\
\hline Mean & & 2.25 & $1.42^{*}$ & $1.33 t$ & 0.33 & 0.75 & $6.08 \dagger$ \\
\hline
\end{tabular}

Signs of brain ischemic injury were scored as follows: 1, dark or eosinophilic neurons or cerebellar Purkinje cells; 2, moderate edema; and 3, severe edema, infarct foci (local necrosis). The total score is the sum of scores of each specific brain area.

${ }^{*} P<.01$ FDP group versus control group.

$\dagger P<.05$ FDP group versus control group.

more favorable fluid balance in the FDP-treated animals throughout the postoperative period. This observation could argue against the metabolic effects of FDP and rather suggest an antiedemigenic effect of this drug. In the FDPtreated group, a decrease in intracranial pressure was observed only during the rewarming period. Although we can not entirely prove this contention, the increased osmolarity cannot be considered to be the main contributor to brain protection because of its extremely time-limited effect on intracranial pressure. Indeed, FDP was associated with intracranial pressure levels that were the same or slightly higher than those in the control animals during most of the postoperative period.

The tendency toward higher brain levels of glucose, pyruvate, and lactate during the first postoperative hours suggests an increase in anaerobic metabolism in the FDP group. Indeed, these findings confirm our previous observation in a series of 74 animals that underwent a 75 -minute period of HCA in which a temporary increase in brain levels of glucose and lactate immediately after reperfusion was significantly associated with a better survival outcome and a reduced risk of brain infarction. ${ }^{23}$ It has been shown that glucose is consumed anaerobically by astrocytes producing lactate, which in turn is consumed aerobically by neurons after a period of hypoxia. ${ }^{24-26}$ Indeed, it seems that aerobic use of lactate, and not of glucose, fuels the recovery of synaptic function during reoxygenation. ${ }^{24}$ Bliss and Sapolsky ${ }^{25}$ showed that lactate inhibits glucose uptake in cultured hippocampal neurons after hypoxia-ischemia. Marrif and Juurlink $^{26}$ demonstrated that astrocytes have upward regulation of anaerobic glycolytic capacity during hypoxia. This enables them to get enough ATP to survive and to perform such important functions as potassium and glutamate uptake from the extracellular space, thus restoring the cerebral microenvironment after ischemia. Astrocytes can continue to produce lactate until their own glycogen store or delivery of glucose is insufficient. Therefore physiologic compensatory glycolysis is not associated with depletion of glucose from the extracellular space. However, in cases of severe ischemia and glucose depletion, this coupled astrocyticneuronal unit metabolic activity turns to uncompensated glycolysis. In fact, under these extreme conditions astro- 


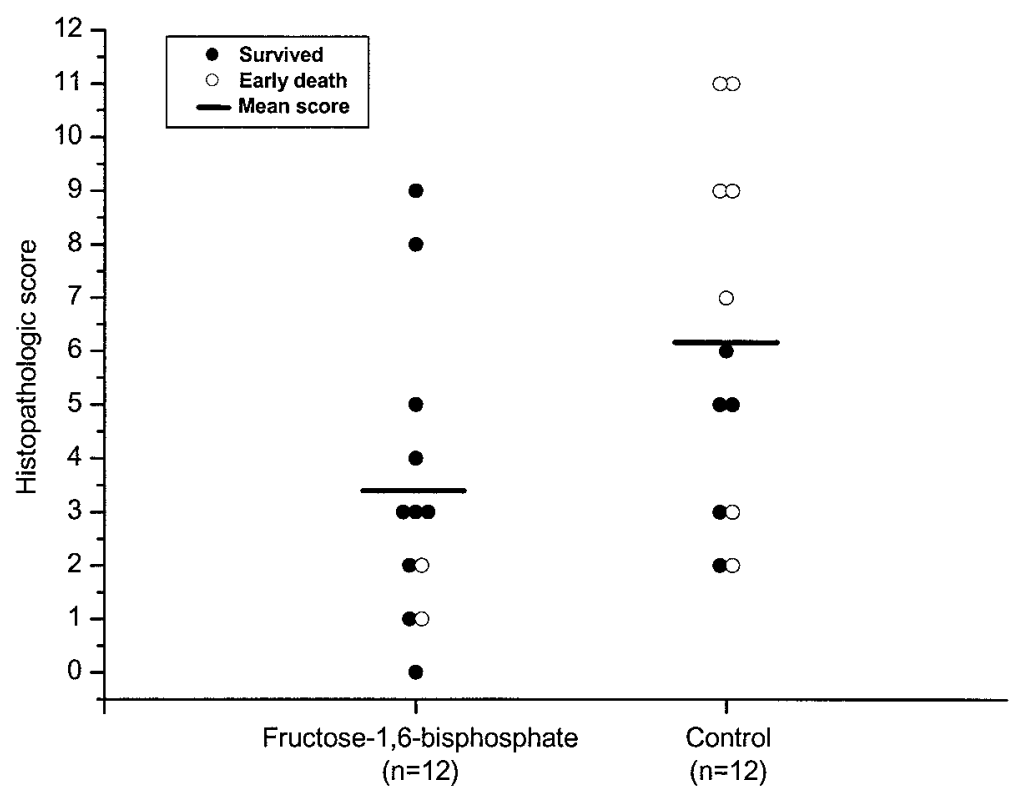

Figure 6. Total brain histopathologic scores from each animal. Higher score indicates more severe brain ischemic injury. Filled circles represent animals alive on postoperative day 7; open circles represent animals dead before postoperative day 7; horizontal lines indicate mean scores.

cytes may not provide enough lactate to the neurons, which may itself revert to glycolysis and compete with astrocytes for extracellular glucose. The results of this study thus suggest that FDP may contribute to support the astrocyticneuronal unit activity by preserving the ATP content and by avoiding uncompensated glycolysis.

In conclusion, the intravenous administration of two $500-\mathrm{mg} / \mathrm{kg}$ doses of FDP before and after HCA in a surviving porcine model was associated with better survival, behavioral outcome, and histopathologic findings. The observed lower brain glycerol levels and the higher brain glucose, pyruvate, and lactate levels suggest that this drug exerts supportive effects on brain metabolism.

We express our gratitude to Janne Heikkinen, MS, Erkka Rönkä, MS, Seija Seljänperä, RN, Veikko Lähteenmäki, and Kauko Korpi, RN, for technical assistance, to Ville Jäntti, MD, $\mathrm{PhD}$, and Pasi Lepola, MSc, for analyzing the EEG data, to the Laboratory of the Oulu University Hospital for analyzing the blood samples, and to the personnel of the Animal Research Center of the Oulu University and its director Hanna-Marja Voipio, DVM, PhD, for providing facilities. We express our gratitude to Outi Ryymin, MSc (Pharm), and Sirpa Ämmälä, MSc (Pharm), for assisting in the study random assignment, and to Dr Bruno Viglianti, Medical Assistant and Pharmacovigilance Manager, Biomedica Foscama, Ferentino, Italy, for providing us with fructose-1,6-bisphosphate (Esafosfina).

\section{References}

1. Bickler PE, Kelleher JA. Fructose-1,6-bisphosphate stabilizes brain intracellular calcium during hypoxia in rats. Stroke. 1992;23:1617-22.
2. Hassinen IE, Nuutinen EM, Ito K, Nioka S, Lazzarino G, Giardina B, et al. Mechanism of the effect of exogenous fructose 1,6-bisphosphate on myocardial energy metabolism. Circulation. 1991;83:584-93.

3. Nuutinen EM, Lazzarino G, Giardina B, Hassinen IE. Effect of exogenous fructose-1,6-bisphosphate on glycolysis in the isolated perfused rat heart. Am Heart J. 1991;122:523-7.

4. Tavazzi B, Starnes JW, Lazzarino G, Di Pierro D, Nuutinen EM, Giardina B. Exogenous fructose-1,6-bisphosphate is a metabolizable substrate for the isolated normoxic rat heart. Basic Res Cardiol. 1992;87:280-9.

5. Gregory GA, Yu AC, Chan PH. Fructose-1,6-bisphosphate protects astrocytes from hypoxic damage. J Cereb Blood Flow Metab. 1989; 9:29-34.

6. Farias LA, Smith EE, Markov AK. Prevention of ischemic-hypoxic brain injury and death in rabbits with fructose-1,6-diphosphate. Stroke. 1990;21:606-13.

7. Sola A, Berrios M, Sheldon RA, Ferriero DM, Gregory GA. Fructose1,6-bisphosphate after hypoxic ischemic injury is protective to the neonatal rat brain. Brain Res. 1996;741:294-9.

8. LeBlanc MH, Farias LA, Evans OB, Vig V, Smith EE, Markov AK. Fructose-1,6-bisphosphate, when given immediately before reoxygenation, or before injury, does not ameliorate hypoxic ischemic injury to the central nervous system in the newborn pig. Crit Care Med. 1991;19:75-83.

9. Behringer W, Kentner R, Wu X, Tisherman SA, Radovsky A, Stezosky WS, et al. Fructose-1,6-bisphosphate and MK-801 by aortic arch flush for cerebral preservation during exsanguination cardiac arrest of 20 min in dogs: an exploratory study. Resuscitation. 2001; 50:205-16.

10. Rimpiläinen J, Pokela M, Kiviluoma K, Vainionpää V, Hirvonen J, Ohtonen P, et al. The $N$-methyl-D-aspartate antagonist memantine has no neuroprotective effect during hypothermic circulatory arrest: a study in the chronic porcine model. J Thorac Cardiovasc Surg. 2001; 121:957-68

11. Rimpiläinen J, Pokela M, Kiviluoma K, Anttila V, Vainionpää V, Hirvonen J, et al. Leukocyte filtration improves brain protection after a prolonged period of hypothermic circulatory arrest: a study in a chronic porcine model. J Thorac Cardiovasc Surg. 2000;120:1131-41. 
12. Rimpiläinen J, Romsi P, Pokela M, Hirvonen J, Vainionpää V, Kiviluoma $\mathrm{K}$, et al. Lamotrigine plus leukocyte filtration as a neuroprotective strategy in experimental hypothermic circulatory arrest. Ann Thorac Surg. 2002;73:163-72.

13. Romsi P, Heikkinen J, Biancari F, Pokela M, Rimpiläinen J, Vainionpää V, et al. Prolonged mild hypothermia after experimental hypothermic circulatory arrest in a chronic porcine model. $J$ Thorac Cardiovasc Surg. 2002;123:724-34.

14. Romsi P, Rönkä E, Kiviluoma K, Vainionpää V, Hirvonen J, Mennander $\mathrm{A}$, et al. Potential neuroprotective benefits of erythropoietin during experimental hypothermic circulatory arrest. J Thorac Cardiovasc Surg. 2002;124:714-23.

15. Lazzarino G, Cattani L, Costrini R, Mulieri L, Candiani A, Galzigna L. Increase of intraerythrocytic fructose-1,6-diphosphate after incubation of whole human blood with fructose-1,6-diphosphate. Clin Biochem. 1984;17:42-5.

16. Markov AK, Neely WA, Didlake RH, Terry J, Causey A, Lehan PH. Metabolic responses to fructose-1,6-diphosphate in healthy subjects. Metabolism. 2000;49:698-703.

17. Cattani L, Costrini R, Cerilli C, Rigobello MP, Bianchi M, Galzigna L. Fructose-1, 6-diphosphate dependence on the toxicity and uptake of potassium ions. Agressologie. 1980;21:263-4.

18. Tavazzi B, Cerroni L, Di Pierro D, Lazzarino G, Nuutinen M, Starnes JW, et al. Oxygen radical injury and loss of high-energy compounds in anoxic and reperfused rat heart: prevention by exogenous fructose1,6-bisphosphate. Free Radic Res Commun. 1990;10:167-76.
19. Cacioli D, Clivati A, Pelosi P, Megevand J, Galeone M. Haemorheological effects of fructose-1,6-diphosphate in patients with lower extremity ischaemia. Curr Med Res Opin. 1988;10:668-74.

20. Gobbel GT, Chan TY, Gregory GA, Chan PH. Response of cerebral endothelial cells to hypoxia: modification by fructose-1,6-bisphosphate but not glutamate receptor antagonists. Brain Res. 1994;653:23-30.

21. Takeuchi K, Cao-Danh H, Friehs I, Glynn P, D’Agostino D, Simplaceanu E, et al. Administration of fructose 1,6-diphosphate during early reperfusion significantly improves recovery of contractile function in the postischemic heart. J Thorac Cardiovasc Surg. 1998;116:335-43.

22. Trimarchi GR, De Luca R, Campo GM, Scuri R, Caputi AP. Protective effects of fructose-1,6-bisphosphate on survival and brain putrescine levels during ischemia and recirculation in the Mongolian gerbil. Stroke. 1990;21 Suppl:IV171-3.

23. Pokela M, Biancari F, Rimpiläinen J, Romsi P, Hirvonen J, Vainionpää $\mathrm{V}$, et al. The role of cerebral microdialysis in predicting the outcome after experimental hypothermic circulatory arrest. Scand Cardiovasc J. 2001;35:395-402.

24. Schurr A, Payne RS, Miller JJ, Rigor BM. Brain lactate, not glucose, fuels the recovery of synaptic function from hypoxia upon reoxygenation: an in vitro study. Brain Res. 1997;744:105-11.

25. Bliss TM, Sapolsky RM. Interactions among glucose, lactate and adenosine regulate energy substrate utilization in hippocampal cultures. Brain Res. 2001;899:134-41.

26. Marrif H, Juurlink BH. Astrocytes respond to hypoxia by increasing glycolytic capacity. J Neurosci Res. 1999;57:255-60.

\section{Targeted}

The Journal of Thoracic and Cardiovascular Surgery gives you two tables of contents.

The condensed table of contents tells you at a glance what topics and authors are presented each month. The expanded table of contents gives you a brief abstract of each article. You select only those articles of most interest to you for further reading. 